\title{
PRODUÇÃO DE GIRASSOL SOB ESTRESSE SALINO E ADUBAÇÃO NITROGENADA ${ }^{(1)}$
}

\author{
Reginaldo Gomes Nobre ${ }^{(2)}$, Hans Raj Gheyi ${ }^{(3)}$, Frederico Antonio \\ Loureiro Soares $^{(4)} \&$ José Alberto Ferreira Cardoso ${ }^{(5)}$
}

\begin{abstract}
RESUMO
A limitada disponibilidade de águas de baixa salinidade na região semiárida brasileira faz com que os produtores utilizem, na irrigação, águas com teores salinos de moderado a alto. Considerando que o girassol (Helianthus annuus L.) vem ganhando destaque nessa região por se caracterizar como fonte potencial de energia renovável, realizou-se esta pesquisa visando avaliar a sua produção sob diferentes níveis de salinidade da água de irrigação (CEa) e doses de adubação nitrogenada, em experimento conduzido em casa de vegetação da Universidade Federal de Campina Grande (UFCG), entre julho e outubro de 2009. Utilizou-se a aleatorização em bloco, testando-se cinco níveis de CEa $\left(0,5\right.$ - controle; 1,$\left.6 ; 2,7 ; 3,8 ; \mathrm{e}_{4,9} \mathrm{dS} \mathrm{m}^{-1}\right) \mathrm{e}$ quatro doses de adubação nitrogenada $(50,75,100$ e $125 \%$ da dose indicada para ensaios em vaso), em esquema fatorial 5 x 4, com três repetições. A salinidade da água de irrigação e a adubação nitrogenada afetam as plantas de girassol de forma independente. A salinidade da água de irrigação a partir de $0,5 \mathrm{dS} \mathrm{m}^{-1}$ altera linear e negativamente a área foliar, a matéria seca da parte aérea e das raízes, a massa e produção total de aquênios e o índice de colheita, enquanto a duração do ciclo da cultura e o intervalo do tempo entre a formação e maturação fisiológica dos aquênios diminuem e sua massa aumenta com as doses de $\mathrm{N}$.
\end{abstract}

Termos de indexação: Helianthus annuus L., produtividade, condutividade elétrica.

\footnotetext{
(1) Trabalho realizado durante o Pós-Doutorado (CNPq/INCTSal/UFCG). Recebido para publicação em abril de 2010 e aprovado em março de 2011.

(2) Professor Adjunto, CCTA/UAGRA, Universidade Federal de Campina Grande - UFCG. Rua Coronel João Leite 517, Centro, CEP 58800-000 Pombal (PB). E-mail: rgomesnobre@ccta.ufcg.edu.br

(3) Pesquisador Visitante Nacional Senior (CAPES) NEAS/UFRB. Cruz das Almas (BA). Bolsista CNPq. E-mail: hans@pq.cnpq.br

(4) Professor do Instituto Federal Goiano, Campus Rio Verde (GO). E-mail: fredalsoares@hotmail.com

(5) Estudante de Graduação em Engenharia Agrícola, UFCG. Bolsista IC/CNPq/INCTSal. E-mail: j_alberto_20@hotmail.com
} 


\title{
SUMMARY: SUNFLOWER PRODUCTION UNDER SALINE STRESS AND NITROGEN FERTILIZATION
}

\begin{abstract}
The limited availability of low-salinity water in Brazilian semiarid region causes producers to use water of moderate to high salinity for irrigation. In view of the increasing importance of sunflower (Helianthus annuus L.) in this region as a potential source of renewable energy, this study was conducted to evaluate sunflower crops irrigated with different water salinity levels (ECW) and fertilized with nitrogen. The experiment was conducted in a greenhouse of the Federal University of Campina Grande (UFCG), from July to October 2009, in a randomized block design, to test five ECw levels (0.5 - control, 1.6, 2.7, 3.8, and $4.9 \mathrm{dS} \mathrm{m} \mathrm{m}^{-1}$ ) and four $N$ rates (50, 75, 100 and $125 \%$ of the rate recommended for pot experiments) in a $5 \times 4$ factorial scheme, with three replications. The salinity of irrigation water and nitrogen fertilization affected the sunflower plants in independent ways. Water salinity affected the leaf area, biomass of aerial parts and roots, weight and total production of achenes and harvest index linearly and negatively. Higher $N$ rates on the other hand reduce the crop cycle and period from achene formation to physiologic maturity, and increased its mass.
\end{abstract}

Index terms: Helianthus annuus L., yield, electrical conductivity.

\section{INTRODUÇÃO}

Nas regiões áridas e semiáridas, nas quais se inclui o Nordeste brasileiro, a prática de irrigação consiste na melhor forma de garantir a produção agrícola com segurança; entretanto, o manejo inadequado da irrigação e a existência de elevada evapotranspiração e de precipitações insuficientes para lixiviar os sais do solo contribuem com o acúmulo de sais, causando a salinização das áreas irrigadas.

Conforme Neves et al. (2009), na região semiárida brasileira é comum a utilização de fontes de água com alta concentração de sais, sobretudo de Na, comprometendo a qualidade desse recurso e do próprio solo, em sua utilização na agricultura. Como consequência desse processo, há perda da capacidade produtiva dos solos e enormes prejuízos socioeconômicos.

A salinidade é um dos principais fatores do ambiente que limitam o crescimento e a produtividade de plantas, e essa limitação acontece porque, em condições salinas, ocorre redução na disponibilidade de água às plantas, em razão do abaixamento no potencial osmótico da solução do solo; assim, a planta tende a dispender mais energia para absorver água e nutrientes (Leonardo et al., 2003). Além disso, a salinização leva ao desbalanço nutricional, uma vez que o excesso de Na na solução do solo provoca distúrbio na absorção de nutrientes, alterando as concentrações de nutrientes, como o $\mathrm{Ca}, \mathrm{Mg}$ e K, na planta (Viana et al., 2001).

O efeito osmótico e a toxidez de íons nas culturas têm sido estudados em diversas partes do mundo, porém a contribuição de cada um desses fatores na restrição do crescimento vegetal ainda exige pesquisas. Conforme Ashraf \& Harris (2004), esses efeitos dependem de muitos outros fatores, como espécie, cultivar, estádio fenológico, características dos sais, intensidade e duração do estresse salino, manejo cultural e da irrigação e condições edafoclimáticas.

O girassol (Helianthus annuus L.) responde por cerca de $13 \%$ de todo o óleo vegetal produzido no mundo, tendo apresentado, nos últimos anos, aumento na área cultivada. Além disso, a planta do girassol, os grãos, os restos da cultura e os subprodutos gerados na extração do óleo podem ser usados na alimentação animal. É uma cultura de ampla adaptabilidade climática, alta tolerância à seca e alto rendimento de grãos e de óleo (Prado \& Leal, 2006); contudo, enquanto para várias culturas são encontradas, na literatura, informações sobre o grau de tolerância ao estresse salino, no caso do girassol poucos são os trabalhos referentes aos efeitos da salinidade da água de irrigação e, ou, do solo nos diferentes estádios de desenvolvimento dessa cultura (Ribeiro et al., 2001; Dickmann et al., 2005).

Conforme Miller \& Cramer (2004), a nutrição mineral é um importante fator ambiental, sendo o $\mathrm{N}$ o macronutriente exigido em maior quantidade pelas culturas agrícolas cuja principal fonte é o nitrato. A absorção de nitrato é reduzida sob condições de salinidade, e essa redução altera a assimilação de N necessário à síntese proteica (Rubinigg et al., 2003).

Carvalho \& Pissaia (2002) obtiveram aumento no peso de 1.000 aquênios de girassol cultivado sob plantio direto na palha quando da aplicação de $125 \mathrm{~kg} \mathrm{ha}^{-1} \mathrm{de}$ N. Biscaro et al. (2008), estudando a aplicação parcelada de $\mathrm{N}$ em cobertura (0 a $80 \mathrm{~kg} \mathrm{ha}^{-1}$ de $\mathrm{N}$ ) na cultura do girassol em campo, obtiveram incremento nas variáveis de crescimento e de produção, alcançando, com a dose de $55 \mathrm{~kg} \mathrm{ha}^{-1}$ de $\mathrm{N}$, a máxima eficiência para produção.

Devido à carência de estudos sobre os efeitos da salinidade da água de irrigação no cultivo de girassol, assim como da relação entre salinidade e nutrição das 
plantas, objetivou-se, com este trabalho, determinar os efeitos do estresse salino e da adubação nitrogenada sobre a produção dessa cultura.

\section{MATERIAL E MÉTODOS}

A pesquisa foi conduzida entre julho e outubro de 2009, em casa de vegetação pertencente à Unidade Acadêmica de Engenharia Agrícola da Universidade Federal de Campina Grande (UFCG), Campina Grande, PB, situada a $7^{\circ} 12$ ' 88 " de latitude sul, $35^{\circ} 54$ ' 40 " de longitude oeste e altitude média de $532 \mathrm{~m}$.

Os tratamentos resultaram da combinação de dois fatores: salinidade da água de irrigação (CEa) em cinco níveis ( 0,5 - controle; 1,$\left.6 ; 2,7 ; 3,8 ; \mathrm{e} 4,9 \mathrm{dS} \mathrm{m}^{-1}\right)$ e quatro doses de adubação nitrogenada (50, 75, 100 e $125 \%$ da indicação de adubação nitrogenada (100 mg kg-1) para ensaios em vaso, conforme Novais et al. (1991), correspondendo a $0,96 \mathrm{~g}$ de ureia e $1,47 \mathrm{~g} / \mathrm{vaso}$ de nitrato de potássio). As unidades experimentais foram dispostas em fileira dupla, espaçadas de 1,0 m entre fileiras duplas e $0,6 \mathrm{~m}$ entre fileiras e entre plantas dentro da fileira dupla.

Adicionou-se o $\mathrm{NaCl}$ à água de abastecimento local, visando à obtenção de águas com diferentes condutividades elétricas, cuja quantidade (Q) foi determinada pela equação $\mathrm{Q}\left(\mathrm{mg} \mathrm{L}^{-1}\right)=640 \times \mathrm{CEa}$ $\left(\mathrm{dS} \mathrm{m}^{-1}\right)$, conforme Rhoades et al. (2000), em que a CEa representa o valor desejado da condutividade elétrica da água. As respectivas águas foram acondicionadas em tonéis plásticos de $150 \mathrm{~L}$ de capacidade. Realizou-se a adubação nitrogenada dividida em cinco parcelas, que foram aplicadas aos 10, 20, 30, 40 e 50 dias após a semeadura (DAS).

As sementes de girassol, cultivar Embrapa 122/V2000, foram fornecidas pela Embrapa Soja, escritório de negócios de Dourados, MS. Conforme Embrapa (2006), essa cultivar destaca-se pela precocidade (ciclo de 100 dias), produtividade (em média, $1.800 \mathrm{~kg} \mathrm{ha}^{-1}$ ), qualidade e teor de óleo nos aquênios (em média, $\left.420 \mathrm{~g} \mathrm{~kg}^{-1}\right)$.

Utilizaram-se, no experimento, vasos plásticos de $23 \mathrm{~L}$ de capacidade, preenchidos com $0,8 \mathrm{~kg}$ de brita ( $\mathrm{n}^{\mathrm{o}}$ zero), a qual cobria a base do vaso, seguida de $1,0 \mathrm{~kg}$ de areia lavada e $21 \mathrm{~kg}$ de solo (Neossolo Regolítico eutrófico franco-arenoso), não salino e não sódico, proveniente do município de Campina Grande, PB. As características físicas e químicas do solo utilizado (Quadro 1) foram determinadas conforme método recomendados pela Embrapa (1997). Os vasos possuíam furos na base para permitir a drenagem e, abaixo destes, havia uma bandeja plástica, para acompanhamento do volume drenado e consumo de água pela cultura.

Realizou-se adubação básica com $13 \mathrm{~g}$ de superfosfato simples e $420 \mathrm{~g}$ (equivalente a $2 \%$ ) de vermicomposto $\left(6,3 \mathrm{~g} \mathrm{~kg}^{-1}\right.$ de $\mathrm{N}, 1,28 \mathrm{~g} \mathrm{~kg}^{-1}$ de $\mathrm{P}$ e $0,53 \mathrm{~g} \mathrm{~kg}^{-1} \mathrm{de} \mathrm{K}$ ) por vaso, visando melhorar as propriedades físicas, químicas e biológicas do solo, de forma a aumentar a capacidade de retenção e infiltração de água no solo. Ao se adicionar o vermicomposto, são adicionados, em cada tratamento, $126 \mathrm{mg} \mathrm{kg}^{-1}$ de $\mathrm{N}$ no solo (420 x 6,3/21). Isso resulta nos seguintes tratamentos de adição de N: 176, 201, 226 e $251 \mathrm{mg} \mathrm{kg}^{-1}$ de $\mathrm{N}$ no solo, considerando um índice de eficiência no primeiro cultivo de 1,00 . Ao se considerar um índice de eficiência de 0,50 para o primeiro cultivo (CQFSRS/SC, 2004), as doses passam a ser: 113, 138, 163 e $188 \mathrm{mg} \mathrm{kg}^{-1}$ de N no solo. Após o acondicionamento do material do solo nos vasos, determinou-se, conforme tratamento, o volume de água necessário para o solo atingir a capacidade de campo, por meio do método de saturação por capilaridade, seguida por drenagem livre.

Foram semeadas, em 27 de julho de 2009, 12 sementes de girassol por vaso a $4 \mathrm{~cm}$ de profundidade, distribuídas de forma equidistante. A emergência das plântulas teve início no terceiro dia após a semeadura (DAS) e continuou até o décimo dia, no qual foi realizado o primeiro desbaste, deixando-se três plantas de melhor vigor por vaso. Aos 20 e 26 DAS, foram realizados novos desbastes, quando então se eliminou uma planta/vaso.

As irrigações foram realizadas no final da tarde (17 h), segundo um turno de rega de 3 dias, a partir da semeadura até os $22 \mathrm{DAS}$, aplicando-se $300 \mathrm{~mL}$ por vaso, em base de trabalho anterior (Nobre et al., 2009). Posteriormente, o turno de rega foi reduzido para 2 dias, e o volume de água aplicado nessas irrigações foi baseado em um experimento anterior (Nobre et al., 2009), em que se levou em consideração o balanço de água na zona radicular.

\section{Quadro 1. Características físicas e químicas do Neossolo utilizado no experimento}

\begin{tabular}{|c|c|c|c|c|c|c|c|c|c|c|}
\hline \multirow{2}{*}{ Densidade } & \multirow{2}{*}{$\begin{array}{l}\text { Porosidade } \\
\text { total }\end{array}$} & \multirow{2}{*}{$\begin{array}{c}\text { Capacidade } \\
\text { de campo }\end{array}$} & \multirow{2}{*}{$\begin{array}{c}\text { Ponto de } \\
\text { murchamento }\end{array}$} & \multirow{2}{*}{$\begin{array}{c}\text { Água } \\
\text { disponível }\end{array}$} & \multicolumn{6}{|c|}{ Complexo sortivo } \\
\hline & & & & & $\mathrm{Ca}^{2+}$ & $\mathrm{Mg}^{2+}$ & $\mathrm{Na}^{+}$ & $\mathbf{K}^{+}$ & $\mathrm{pH}_{\mathrm{ps}}$ & $\overline{\mathrm{CE}_{\mathrm{es}}}$ \\
\hline $\mathrm{kg} \mathrm{dm} \mathrm{m}^{-3}$ & $\%$ & 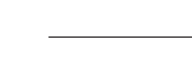 & $\mathrm{g} \mathrm{kg}^{-1}$ & 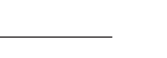 & 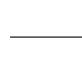 & - $\mathrm{cmol}$ & $g^{-1}$ & - & - & $\mathrm{dS} \mathrm{m}^{-1}$ \\
\hline 1,45 & 42,35 & 83,60 & 22,90 & 60,70 & 1,87 & 1,05 & 0,06 & 0,23 & 6,15 & 0,51 \\
\hline
\end{tabular}

$\mathrm{Ca}^{2+}$ e $\mathrm{Mg}^{2+}$ extraídos com KCl $1 \mathrm{~mol} \mathrm{~L}^{-1} \mathrm{pH}$ 7,0; $\mathrm{Na}^{+} \mathrm{e} \mathrm{K}{ }^{+}$extraídos utilizando-se $\mathrm{NH}_{4} \mathrm{OAc} 1 \mathrm{~mol} \mathrm{~L}^{-1} \mathrm{pH}$ 7,0. 
Durante a condução do experimento foram realizados os seguintes tratos culturais: tutoramento das plantas, eliminação manual das plantas daninhas e escarificação superficial do solo, antes de cada irrigação, e pulverizações, a cada 30 dias, com produtos indicados para controle preventivo de insetos (Imidacloprido - Confidor $700 \mathrm{WG}-0,5 \mathrm{~g} \mathrm{~L}^{-1}$ ) e doenças fúngicas (Triazol - Rival $200 \mathrm{EC}-0,5 \mathrm{~g} \mathrm{~L}^{-1}$ ). O girassol é uma planta de polinização cruzada, necessitando da presença de insetos polinizadores. Como o experimento foi conduzido em casa de vegetação, impossibilitando a polinização natural, empregou-se a polinização artificial cruzada.

No momento em que as plantas atingiram o estádio de maturação fisiológica dos aquênios, ou seja, quando estes se apresentavam com massa dura (Silva et al., 2007), fez-se a suspensão da irrigação. De acordo com Connor \& Hall (1997), esse estádio fenológico é denominado "R9", cujo capítulo se encontra inclinado para baixo, com dorso e brácteas de cor entre amarelo e castanho.

Para análise do efeito dos tratamentos sobre a produção do girassol, foram mensurados: a área foliar (AF); a massa de matéria seca da parte aérea (MSPA) e de raiz (MSR); a duração (em dias) do ciclo da cultura (DCC) e da formação, até a maturação fisiológica dos aquênios (DFMFA); a massa de 100 aquênios (M100); a produção de aquênio por planta (PA); e o índice de colheita (IC).

Aos 26 e 50 DAS, determinou-se a área foliar (AF), conforme Maldaner et al. (2009), usando-se a seguinte equação: $\mathrm{AF}=1,7582 \mathrm{~L}^{1,7067}$, sendo o 'L' a largura do limbo foliar; segundo esses autores, o modelo não linear citado é o mais exato e adequado para se estimar a AF em girassol.
Passados 10 dias após a suspensão da irrigação, a haste de cada planta foi cortada rente ao solo e, em seguida, foram separadas as distintas partes (caule, folha e capítulo) e acondicionadas em sacos de papel, os quais foram posteriormente conduzidos à estufa com ventilação forçada de ar, a $65{ }^{\circ} \mathrm{C}$, até obtenção de massa constante, para determinação da MSPA. As raízes das plantas foram coletadas mediante lavagem e, tal como as demais partes da planta, foram postas para secar em estufa, visando mensurar a MSR.

Os aquênios de cada capítulo foram debulhados manualmente antes da condução dos capítulos à estufa e, posteriormente, separados em aquênios granados e não granados. Consideraram-se aquênios não granados aqueles que não se desenvolveram, observando-se apenas o pericarpo dos frutos. Posteriormente, e utilizando os aquênios de aparência normal, efetuouse a determinação da M100 e da PA.

O IC foi obtido pela relação entre a massa de matéria seca de aquênios e massa de matéria seca total da planta.

No final do ciclo, determinou-se a condutividade elétrica da água de drenagem (CEd) e multiplicou-se por 0,45 - fator este anteriormente estabelecido (Travassos et al., 2011) para mesmo solo e cultura onde se estimou o valor de condutividade elétrica do estrato de saturação do solo. Salienta-se que Ayers \& Westcot (1999) relatam ser a relação igual a 0,5, para um solo de textura média.

Os dados obtidos foram avaliados mediante análise de variância e, nos casos de significância, realizou-se análise de regressão polinomial linear, quadrática e cúbica, utilizando-se do software estatístico SISVARESAL (Ferreira, 2003). Em razão da homogeneidade dos dados, percebida pelos baixos valores de coeficiente de variação (Quadro 2), não foi necessário realizar análise exploratória dos dados.

Quadro 2. Resultado do teste F para área foliar (AF) aos 26 e 50 DAS, massa de matéria seca da parte aérea (MSPA) e de raiz (MSR) na época de colheita, duração do ciclo da cultura (DCC), duração entre formação e maturação fisiológica dos aquênios (DFMFA), massa de 100 aquênios (M100), produção de aquênios (PA) por planta e índice de colheita (IC) do girassol, em função de diferentes níveis da salinidade da água de irrigação e doses de nitrogênio

\begin{tabular}{|c|c|c|c|c|c|c|c|c|c|}
\hline \multirow{2}{*}{ Fonte de variação } & \multicolumn{9}{|c|}{ Teste F } \\
\hline & 26 DAS & 50 DAS & MSPA & $\operatorname{MSR}^{(1)}$ & $\mathrm{DCC}$ & DFMFA & M100 & PA & IC \\
\hline & \multicolumn{2}{|c|}{$-\mathrm{AF}\left(\mathrm{cm}^{2}\right)-$} & \multicolumn{2}{|c|}{ — g/planta - } & \multicolumn{2}{|c|}{$\longrightarrow$ dia $\longrightarrow$} & $\mathrm{g}$ & g/planta & $\mathrm{g} \mathrm{g}^{-1}$ \\
\hline Salinidade da água (S) & ns & ** & $* *$ & $* *$ & ns & ns & $* *$ & $* *$ & $* *$ \\
\hline Reg. Linear & - & ** & $* *$ & ** & - & - & $* *$ & $* *$ & $* *$ \\
\hline Reg. Quadrática & - & ns & ns & $\mathrm{ns}$ & - & - & - & $\mathrm{ns}$ & ns \\
\hline Reg. Cúbica & - & $\mathrm{ns}$ & $\mathrm{ns}$ & ns & - & - & - & $\mathrm{ns}$ & ns \\
\hline Doses nitrogênio (D) & $\mathrm{ns}$ & $\mathrm{ns}$ & $\mathrm{ns}$ & ns & $* *$ & * & * & $\mathrm{ns}$ & ns \\
\hline Reg. Linear & - & $* *$ & - & - & $*$ & * & * & - & - \\
\hline Reg. Quadrática & - & $* *$ & - & - & * & * & - & - & - \\
\hline Interação (S x D) & $\mathrm{ns}$ & $\mathrm{ns}$ & $\mathrm{ns}$ & $\mathrm{n}$ & $\mathrm{ns}$ & $\mathrm{ns}$ & $\mathrm{ns}$ & $\mathrm{ns}$ & $\mathrm{ns}$ \\
\hline Bloco & $\mathrm{ns}$ & $\mathrm{ns}$ & $\mathrm{ns}$ & $\mathrm{ns}$ & $\mathrm{ns}$ & $\mathrm{ns}$ & $\mathrm{ns}$ & $\mathrm{ns}$ & ns \\
\hline $\mathrm{CV}(\%)$ & 15,75 & 15,73 & 9,17 & 15,64 & 2,25 & 9,99 & 20,21 & 15,24 & 11,68 \\
\hline
\end{tabular}

(1) Dados transformados em raiz de x. ns, * ${ }^{* *}$ : não significativo e significativo a 5 e $1 \%$. 


\section{RESULTADOS E DISCUSSÃO}

Constatou-se, com base nos resultados do teste $\mathrm{F}$ dos dados (Quadro 2), não haver efeito na interação entre os fatores estudados (salinidade da água de irrigação e doses de adubação nitrogenada) para nenhuma variável analisada, denotando comportamento semelhante das doses de $\mathrm{N}$ dentro da salinidade da água. Gurgel et al. (2010), estudando o crescimento do meloeiro sob estresse salino e adubação potássica, também observaram não haver interação entre esses fatores.

\section{Área foliar}

De acordo com os resultados do teste $\mathrm{F}$ (Quadro 2), $a$ área foliar do girassol variou $(p<0,01)$ em função dos diferentes níveis de salinidade da água de irrigação, apenas na avaliação realizada aos 50 DAS. Nessa ocasião (Figura 1a), o aumento da salinidade da água de irrigação promoveu resposta linear decrescente da área foliar, ocorrendo decréscimo na ordem de 11,9 \% por aumento unitário da CEa, ou seja, redução de $52,5 \%\left(1.448,92 \mathrm{~cm}^{2}\right)$ na AF das plantas irrigadas com água de $4,9 \mathrm{dS} \mathrm{m}^{-1}$, em relação à testemunha. Esse decréscimo da área foliar está relacionado, possivelmente, a um dos mecanismos de adaptação da planta ao estresse salino, diminuindo a superfície transpirante (Tester \& Davenport, 2003) e, consequentemente, a perda de água por transpiração. Essa redução da $\mathrm{AF}$ é um dos mecanismos que a planta usa sob estresse salino para manter o equilíbrio entre a absorção e transpiração - fato esse que pode aumentar a eficiência no uso da água e minimizar o acúmulo de sais na planta.

Devido à carência de resultados de pesquisa que avaliem os efeitos da salinidade da água sobre as variáveis de crescimento do girassol, compararam-se os resultados do presente estudo com os obtidos com outras oleaginosas. Assim, Nery et al. (2009), analisando o crescimento do pinhão-manso sob irrigação com águas de diferentes salinidades, constataram que a $\mathrm{AF}$ foi a variável mais alterada pela salinidade; contudo, o efeito só foi observado a partir dos 79 DAS, cujas reduções da AF das plantas submetidas a CEa variando de 0,6 e $3,0 \mathrm{dS} \mathrm{m}^{-1}$ foram de 33,69 e $42,58 \%$ aos 79 e 163 DAS, respectivamente. Assim como no presente estudo, a AF dessa oleaginosa não foi influenciada significativamente pela CEa na fase inicial de crescimento, denotando ser a cultura mais tolerante aos efeitos salinos nesse estádio de desenvolvimento. Cavalcanti et al. (2005), trabalhando com a mamoneira sob diferentes $\mathrm{CEa}(0,7$ a $4,7 \mathrm{dS} \mathrm{m}^{-1}$ ), também verificaram que o incremento salino contribui para a redução da área foliar das plantas.

$\mathrm{O}$ fator dose de $\mathrm{N}$ não promoveu efeito, em nenhuma das épocas de avaliação, sobre a área foliar, fato esse ocorrido em razão de o vermicomposto aplicado antes da semeadura, que forneceu quantidade equivalente a $126 \mathrm{mg} \mathrm{kg}^{-1} \mathrm{de} \mathrm{N}$ no solo, provavelmente
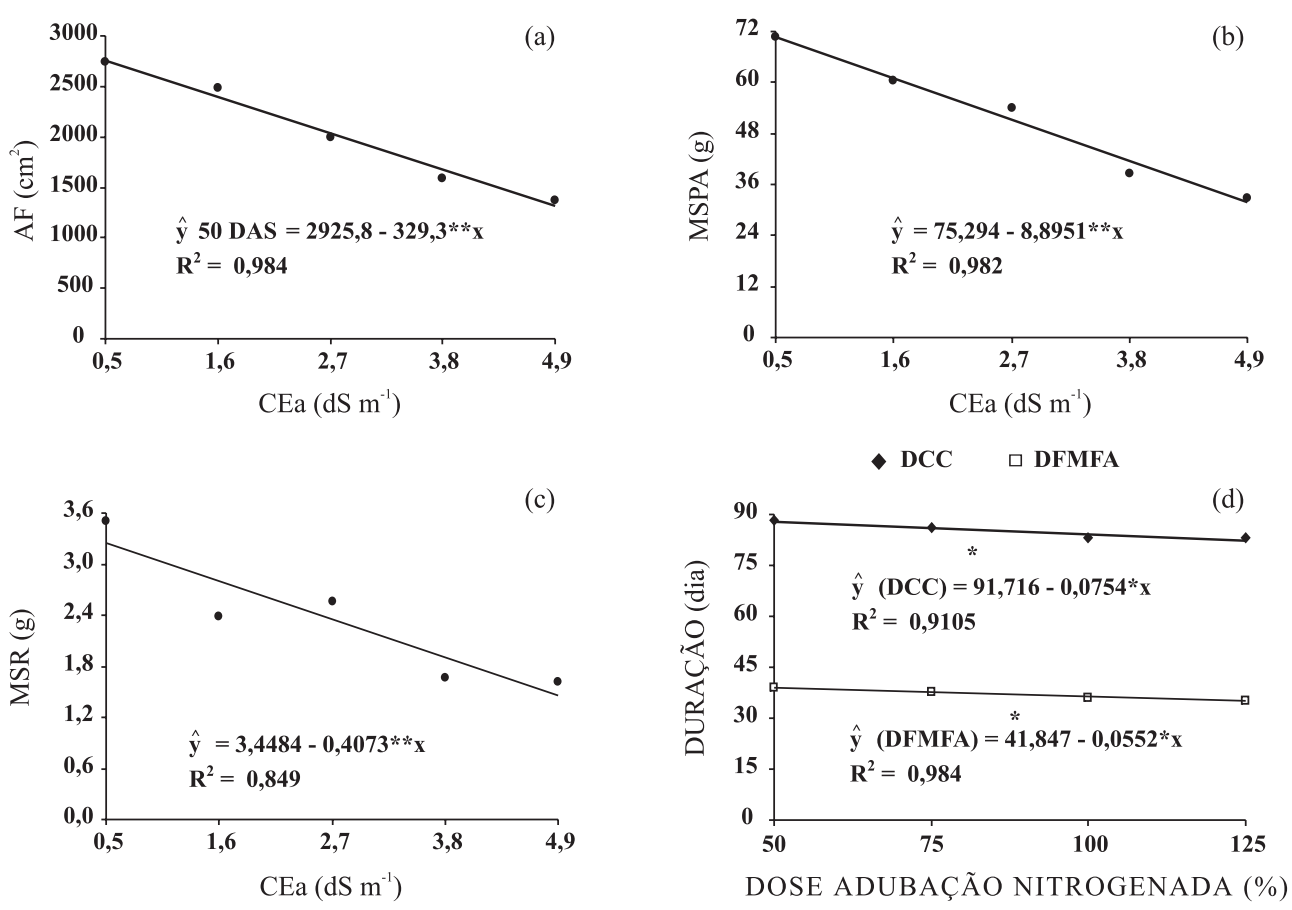

Figura 1. Área foliar - AF aos 50 dias após semeadura (a) e matéria seca da parte aérea - MSPA (b) e de raiz - MSR (c) na época da colheita, em função da condutividade elétrica da água de irrigação (CEa) e duração do ciclo da cultura - DCC e da formação até a maturação fisiológica dos aquênios - DFMFA (d), em função de doses de adubação nitrogenada 
ter mascarado o efeito de doses de $\mathrm{N}$ aplicado. Outrossim, as plantas sob estresse salino, associado à presença do íon $\mathrm{Cl}^{-}$(Popova et al., 2002), tendem a diminuir a assimilação de $\mathrm{N}$ e a síntese de aminoácidos, sendo o motivo primário dessa redução. Bruginski \& Pissaia (2002), estudando o híbrido de girassol M-734 em campo sob doses crescentes de N $\left(0,25,50,75,100\right.$ e $\left.125 \mathrm{~kg} \mathrm{ha}^{-1}\right)$, também não encontraram efeito sobre a área foliar, assim como para número de folhas, altura de plantas e diâmetro do caule. Já para Biscaro et al. (2008), a adubação nitrogenada em cobertura em campo proporcionou aumento nas variáveis de crescimento e de produção do girassol cultivar H358 da Dekalb, em que a dose de máxima eficiência encontrada foi de $55 \mathrm{~kg} \mathrm{ha}^{-1} \mathrm{de}$ $\mathrm{N}$.

\section{Massa de matéria seca da parte aérea e de raiz}

Verifica-se que o fator salinidade da água alterou $(p<0,01)$ as variáveis massa de matéria seca da parte aérea (MSPA) e de raiz (MSR) (Quadro 2). O modelo linear indicou decréscimos iguais para MSPA (Figura 1b) e MSR (Figura 1c) de 12,6\%, por aumento unitário da condutividade elétrica da água de irrigação, ou seja, redução da MSPA de 55,2 \% (39,12 g) e da MSR de 55,2 \% (1,79 g) nas plantas irrigadas com água de $4,9 \mathrm{dS} \mathrm{m}^{-1}$, em relação à testemunha.

Denota-se, conforme resultados para produção de massa de matéria seca das plantas, que o incremento salino promoveu redução na disponibilidade hídrica devido à elevada concentração de sais na zona radicular (comprovada mediante $\mathrm{CE}$ da água de drenagem); consequentemente, o metabolismo vegetal foi reduzido. Segundo Asch et al. (2000), a água de irrigação ou solo contendo concentração salina elevada, ocasionada principalmente pela presença de íons de $\mathrm{Na}^{+}$e $\mathrm{Cl}^{-}$, pode causar disrupção na homeostase do potencial de água e desbalanço iônico na interfase soloplanta e promover toxidez no vegetal, alterando seu crescimento e a produção de matéria seca, além de promover redução na absorção de nutrientes. O incremento salino também prejudicou o desenvolvimento das plantas de algodão e algaroba (Meloni et al., 2001), por meio de reduções na expansão foliar e na massa de matéria fresca e seca da parte aérea e de raízes, além de incrementar a razão raizl parte aérea.

A concentração elevada de sais no solo diminui o potencial osmótico e a disponibilidade de água para plantas. Castro et al. (2006) constataram, em estudo com a cultura do girassol, que o déficit hídrico ocorrido principalmente durante o início do florescimento e enchimento dos grãos promoveu decréscimo na massa de matéria seca total de aquênios e de óleo.

O efeito do estresse salino também é constatado em outras culturas: Oliveira et al. (2008), no caso de algodoeiro, observaram que a salinidade da água de irrigação alterou a massa de matéria seca da parte aérea, decrescendo linearmente $9,7 \%$ por aumento unitário da CEa. Já Costa et al. (2008), com amaranto, constataram tolerância à salinidade da água de irrigação até o limite de $4,5 \mathrm{dS} \mathrm{m}^{-1}$, devido à não verificação de efeito sobre a massa de matéria seca total.

As doses de $\mathrm{N}$ não influenciaram a produção de massa de matéria seca da parte aérea e da raiz (Quadro 2). Essa falta de resposta pode estar associada ao curto ciclo da cultura e ao fato de o vermicomposto misturado ao solo antes da semeadura, que continha $6,3 \mathrm{~g} \mathrm{~kg}^{-1}$ de N no solo (126 mg kg-1 de N no solo), ter atendido às necessidades de $\mathrm{N}$ das plantas para o seu crescimento e desenvolvimento. Outrossim, o vermicomposto ainda continha outros nutrientes $\left(1,28 \mathrm{~g} \mathrm{~kg}^{-1}\right.$ de $\mathrm{P}$ e $0,53 \mathrm{~g} \mathrm{~kg}^{-1}$ de K) que podem ter contribuído para o desenvolvimento do girassol. Segundo Barni et al. (1995), níveis de adubação não evidenciam diferenças no crescimento do girassol quando é alto o nível de fertilidade no solo.

\section{Duração do ciclo da cultura e intervalo entre formação e maturação fisiológica dos aquênios}

Constatou-se efeito (Quadro 2) do fator doses de adubação nitrogenada $(p<0,01)$ para duração do ciclo da cultura (DCC) e para o período da formação à maturação fisiológica dos aquênios (DFMFA) do girassol $(0,01 \leq \mathrm{p}<0,05)$. Diferentemente das variáveis AF, MSPA e MSR, os níveis salinos não promoveram efeito sobre as variáveis DCC e DFMFA (Quadro 2); já Costa et al. (2008) verificaram efeito do estresse salino sobre a duração da fase de crescimento do amaranto, constatando que o aumento da salinidade da água de irrigação $\left(0\right.$ a $\left.4,5 \mathrm{dS} \mathrm{m}^{-1}\right)$ contribuiu para retardar o tempo médio de início de floração.

Destaca-se que os programas brasileiros de melhoramento genético buscam selecionar genótipos de girassol precoces, visando aproveitar a entressafra de culturas como trigo, cevada, cana-de-açúcar, milho, etc. Nesse sentido, conforme estudos de regressão, o efeito das doses de adubação nitrogenada foi linear e decrescente sobre a DCC e a DFMFA (Figura 1d), ocorrendo, nas plantas que receberam maior quantidade de $\mathrm{N}$, redução no ciclo de 5,66 dias e, no período entre formação e maturação de aquênio, de 4,14 dias, em comparação com as que receberam menos N.

Pelas equações de regressão (Figura 1d), verificamse decréscimos de $2,1 \%$ na DCC e $3,53 \%$ na DFMFA por aumento de $25 \%$ na dose de adução nitrogenada estudada (na presença de $2 \%$ de vermicomposto), ou seja, decréscimo de 6,4 e 10,6\%, respectivamente, no intervalo de 50 a $125 \%$ de dose de $\mathrm{N}$.

Conforme Embrapa (2006), a cultivar Embrapa $122 / V-2000$ é indicada para as regiões Sul e Central do Brasil, onde o ciclo vegetativo tem duração de aproximadamente 100 dias. Nas condições em que esta pesquisa foi desenvolvida, observa-se (Figura 1d) que, a partir da dose de $50 \%$ de adubação nitrogenada 
(na presença de $2 \%$ de vermicomposto), ocorreu decréscimo no DCC em comparação com a citação da Embrapa, alcançando a menor DCC (82,29 dias) com dose igual a $125 \%$ de N, ou seja, foi bem mais precoce, o que possibilita sua exploração com eficiência na região Nordeste do Brasil, aproveitando o período chuvoso, que, em geral, se concentra em período médio de 90 dias, assim como a exploração na fase de entressafra ou por contribuir para a realização de um número maior de ciclos por ano. Essa divergência na duração do ciclo do girassol ocorreu por influência, sem dúvida, do aporte de nutrientes (adubação nitrogenada) e, ou, em virtude das condições climáticas locais em comparação com as das regiões Sul e Central do Brasil, pois, segundo Embrapa (2006), o girassol tem seu ciclo aumentado quando cultivado em baixas temperaturas, requerendo temperaturas na faixa entre 24 e $30{ }^{\circ} \mathrm{C}$ para seu ótimo desenvolvimento; no presente estudo, a temperatura média foi de $26{ }^{\circ} \mathrm{C}$. Em relação ao fotoperíodo, o girassol é classificado como espécie insensível.

\section{Produção de aquênio e índice de colheita}

Verificou-se efeito dos níveis salinos $(p<0,01)$ e das doses de $\mathrm{N}(0,01 \leq \mathrm{p}<0,05)$ sobre a massa de 100 aquênios (Quadro 2). De acordo com as equações de regressão, o modelo ao qual os dados se ajustaram melhor foi o linear, indicando que o incremento salino da água de irrigação (Figura 2a) promoveu decréscimo de 10,70 \% por aumento unitário da CEa na M100, ou seja, redução de $2,74 \mathrm{~g}$, quando as plantas foram submetidas a $\mathrm{CEa}$ de $4,9 \mathrm{dS} \mathrm{m}^{-1}$, em relação às irrigadas com água de $0,5 \mathrm{dS} \mathrm{m}^{-1}$. Considerando que a massa dos aquênios é resultado da capacidade da planta em suprir suas necessidades hídricas e nutricionais até o limite potencial de cada cultivar, infere-se que, neste estudo, estas, quando submetidas ao acréscimo salino da água, tiveram reduções na disponibilidade de elementos essenciais ao seu desenvolvimento.

A salinidade tende a reduzir a disponibilidade hídrica às plantas, devido principalmente ao efeito osmótico, prejudicando a produção de aquênios, como verificado por Castro et al. (2006) com o híbrido de girassol Morgan 738. Entretanto, esse efeito não foi observado por Travassos et al. (2011) com a cultivar Embrapa 122/V-2000 sob diferentes níveis salinos (CEa entre 0,5 e $5,0 \mathrm{dS} \mathrm{m}^{-1}$ ).

Silva et al. (2007), no caso de girassol - genótipos H250 e H251 - cultivado na entressafra, não encontraram efeito do fator lâmina de água entre 117,20 e $522,14 \mathrm{~mm}$ sobre a massa de 1.000 aquênios, mas verificaram massa média de 100 aquênios desses genótipos inferior à do presente trabalho quando da utilização de água com salinidade de até $2,7 \mathrm{dS} \mathrm{m}^{-1}$, denotando haver, nos aquênios, maior quantidade de óleo e, ou, de fibras, ou, provavelmente, pelo fato de a cultivar (Embrapa 122/V-2000) ser mais tolerante aos sais.

Em relação ao fator doses de $\mathrm{N}$, o efeito sobre a M100 foi linear e crescente (Figura 2b), ocorrendo incremento de 6,9\% por aumento de $25 \%$ na dose de $\mathrm{N}$ (na presença de $2 \%$ de vermicomposto). As plantas submetidas à maior dose de adubação nitrogenada apresentaram M100 igual a 4,87 g; já Braz et al. (2009) obtiveram, em experimento de campo, melhor qualidade fisiológica de aquênios de girassol no estabelecimento das plântulas e no desempenho das plantas com aplicação de $50 \mathrm{~kg} \mathrm{ha}^{-1}$ de $\mathrm{N}$, provavelmente pelo maior suprimento de nutrientes.
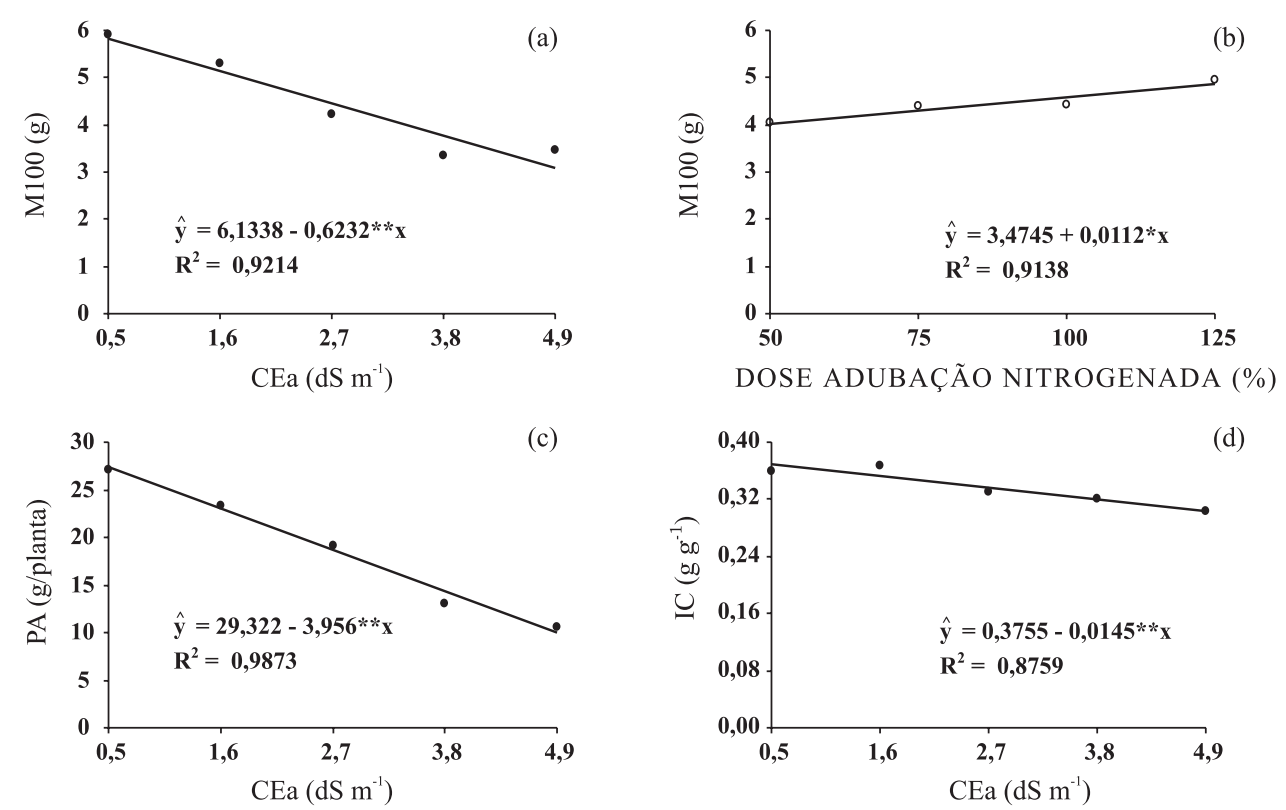

Figura 2. Massa de 100 aquênios - M100, em função da condutividade elétrica da água de irrigação (CEa) (a) e de doses de adubação nitrogenada (b), produção de aquênios por planta - PA (c) e índice de colheita IC (d) de girassol, em função da CEa. 
Quanto à produção de aquênios por capítulo (PA), o fator salinidade da água foi o único a influenciar $(\mathrm{p}<0,01)$ essa variável (Quadro 2). Foi utilizada a equação de regressão do modelo linear (Figura 2C), que foi o que melhor se ajustou aos dados: ela evidencia decréscimo na PA de 14,5 \% por elevação unitária da condutividade elétrica da água de irrigação. Travassos et al. (2011), após conduzir experimento em casa de vegetação com o girassol cv. Embrapa 122/V-2000 sob irrigação com águas de diferentes salinidades $(0,5$ a 5,0 d $\mathrm{S} \mathrm{m}^{-1}$ ), constatou que a produção de aquênios decresceu 10,6\% por incremento unitário da condutividade elétrica da água de irrigação.

Segundo Gulzar et al. (2003), os estresses provocados pelo excesso de íons, em geral, diminuem a assimilação de $\mathrm{CO}_{2}$, condutância estomática, transpiração e fotossíntese das plantas e, por conseguinte, acabam por prejudicar a produção e a produtividade das culturas. Constatou-se, no presente estudo, que o estresse salino reduziu linearmente a área foliar aos 50 DAS, bem como, na época da colheita, a massa de matéria seca da parte aérea e de raiz e a massa de 100 aquênios; em consequência, a produção também decresceu.

A redução de 17,4 g/planta (63,66 \%) nas plantas submetidas à $\mathrm{CEa}$ de $4,9 \mathrm{dS} \mathrm{m}^{-1}$, em relação às irrigadas com água de $0,5 \mathrm{dS} \mathrm{m}^{-1}$, obtendo-se, nessas plantas, uma PA de 27,34 g/planta (Figura 2c), é menor que a encontrada por Braz et al. (2009) em experimento de campo com a mesma cultivar. Essa diferença pode ter ocorrido em razão de o presente experimento ter sido realizado em casa de vegetação, onde a polinização foi feita de forma manual.

Observa-se (Quadro 2) a ocorrência de efeitos $(\mathrm{p}<0,01)$ apenas do fator salinidade da água de irrigação sobre o índice de colheita (IC) das plantas de girassol. De acordo com a equação de regressão (Figura 2d), o modelo linear indicou decréscimo no IC de 3,9\% por aumento unitário da condutividade elétrica da água de irrigação, isto é, decréscimo de $17,3 \%$ no IC das plantas irrigadas com água de $4,9 \mathrm{dS} \mathrm{m}^{-1}$, em relação ao controle $\left(\mathrm{CEa}=0,5 \mathrm{dS} \mathrm{m}^{-1}\right)$.

\section{CONCLUSÕES}

1. A salinidade da água de irrigação e a adubação nitrogenada afetam de forma distinta as plantas de girassol, sem haver, no entanto, interação entre elas.

2. A área foliar, a massa de matéria seca da parte aérea e das raízes, a massa de 100 aquênios, a produção de aquênios por planta e o índice de colheita do girassol decrescem de forma linear a partir da salinidade da água de irrigação de $0,5 \mathrm{dS} \mathrm{m} \mathrm{m}^{-1}$.

3. A duração do ciclo da cultura do girassol e do intervalo de tempo entre a formação e a maturação fisiológica dos aquênios diminui a sua massa e aumenta com as doses de N.

\section{AGRADECIMENTOS}

Ao Instituto Nacional de Ciência e Tecnologia em Salinidade - INCTSal e ao Conselho Nacional de Pesquisa e Desenvolvimento - CNPq, pela concessão do auxílio financeiro e bolsa PDJ ao primeiro autor para a realização deste trabalho; e à Embrapa Soja, escritório de negócios de Dourados, MS, pelo fornecimento das sementes de girassol.

\section{LITERATURA CITADA}

ASCH, F.; DINGKUHN, M. \& DORFFING, K. Salinity increases $\mathrm{CO}_{2}$ assimilation but reduces growth in field grown irrigated rice. Plant Soil, 218:1-10, 2000.

ASHRAF M. \& HARRIS, P.J.C. Potential biochemical indicators of salinity tolerance in plants. Plant. Sci., 166:3-16, 2004.

AYERS, R.S. \& WESTCOT, D.W. A qualidade da água na agricultura. Campina Grande, Universidade Federal da Paraíba, 1999. 153p. (Estudos FAO - Irrigação e Drenagem, 29)

BARNI, N.A.; BERLATO, M.A.; SANTOS, A.O. \& SARTORI, G. Análise de crescimento do girassol em resposta a cultivares, níveis de adubação e épocas de semeadura. Pesq. Agropec. Gaúcha, 1:167-184, 1995.

BISCARO, G.A.; MACHADO, J.R.; TOSTA, M.S.; MENDONÇA, V.; SORATTO, R.P. \& CARVALHO, L.A. Adubação nitrogenada em cobertura no girassol irrigado nas condições de Cassilândia-MS. Ci. Agrotec., 32:1366-1373, 2008.

BRAZ, M.R.S. \& ROSSETTO, C.A.V. Estabelecimento de plântulas e desempenho de plantas em resposta ao vigor dos aquênios de girassol. Ci. Rural, 39:1997-2003, 2009.

BRUGINSKI, D.H. \& PISSAIA, A. Cobertura nitrogenada em girassol sob plantio direto na palha: II - morfologia da planta e partição de massa seca. Sci. Agr., 3:47-53, 2002.

CARVALHO, D.B. \& PISSAIA, A. Cobertura nitrogenada em girassol sob plantio direto na palha. Sci. Agr., $1 / 2: 41-45$, 2002.

CASTRO, C.; MOREIRA, A.; OLIVEIRA, R.F. \& DECHEN, A.R. Boro e estresse hídrico na produção do girassol. Ci. Agrotec., 30:214-220, 2006.

CAVALCANTI, M.L.F.; FERNANDES, P.D.; GHEYI, H.R.; BARROS JÚNIOR, G.; SOARES, F.A.L. \& SIQUEIRA, E.C. Tolerância da mamoneira BRS 149 à salinidade: Germinação e características de crescimento. R. Bras. Eng. Agric. Amb., 9:57-61, 2005. (Suplemento)

COMISSÃO DE QUÍMICA E FERTILIDADE DO SOLO CQFSRS/SC. Manual de recomendações de adubação e calagem para os estados do Rio Grande do Sul e Santa Catarina. Porto Alegre, SBCS - Núcleo Regional Sul, 2004. $394 \mathrm{p}$. 
CONNOR, J.D. \& HALL, A.J. Sunflower physiology. In: SCHNEIDER, A.A., ed. Sunflower technology and production. Madison, ASA/CSSA/SSSA, 1997. p.113-181. (Series of Monographs, 35)

COSTA, D.M.A.; MELO, H.N.S.; FERREIRA, S.R. \& HOLANDA, J.S. Crescimento e desenvolvimento do amaranto (Amaranthus spp.) sob estresse salino e cobertura morta. R. Bras. Ci. Solo, 32:43-48, 2008.

DICKMANN, L.; CARVALHO, M.A.C.; BRAGA, L.F.B. \& SOUSA, M.P. Comportamento de sementes de girassol (Helianthus annuus L.) submetidas a estresse salino. $\mathrm{R}$. Ci. Agro-Ambi., 3:64-75, 2005.

EMPRESA BRASILEIRA DE PESQUISA AGROPECUÁRIA EMBRAPA. Manual de métodos de análise de solo. 2.ed. Rio de Janeiro, Centro Nacional de Pesquisa de Solos, 1997. 212p.

EMPRESA BRASILEIRA DE PESQUISA AGROPECUÁRIA EMBRAPA. Girassol Embrapa 122/V-2000. Londrina, 2006. (Folder n. 04/2006).

FERREIRA, D.F. SISVAR 4.6 sistema de análises estatísticas. Lavras, Universidade Federal de Lavras, 2003.

GULZAR, S.; KHAN, M.A. \& UNGAR, I.A. Salt tolerance of a coastal salt marsh grass. Soil Sci. Plant Anal., 34:2595$2605,2003$.

GURGEL, M.T.; UYEDA, C.A.; GHEYI, H.R.; OLIVEIRA, F.H.T.; FERNANDES, P.D. \& SILVA, F.V. Crescimento de meloeiro sob estresse salino e doses de potássio. R. Bras. Eng. Agric. Amb., 14:3-10, 2010.

LEONARDO, M.; BROETTO, F.; BÔAS, R.L.V.; ALMEIDA, R.S.; GODOY, L.J.G. \& MARCHESE, J.A. Estresse salino induzido em plantas de pimentão e seus efeitos na produção de frutos. Hortic. Bras. 21:1-4, 2003.

MALDANER, I.C.; HELDWEIN, A.B.; LOOSE, L.H.; LUCAS, D.D.P.; GUSE, F.I. \& BORTOLUZZI, M.P. Modelos de determinação não-destrutiva da área foliar em girassol. Ci. Rural, 39:1356-1361, 2009.

MELONI, D.A.; OLIVA, M.A.; RUIZ, H.A. \& MARTINEZ, C.A. Contribution of proline and inorganic solutes to osmotic adjustment in cotton under salt stress. J. Plant Nutr., 24:599-612, 2001.

MILLER, A.J. \& CRAMER, M.D. Root nitrogen acquisition and assimilation. Plant Soil, 274:3-6, 2004.

NERY, A.R.; RODRIGUES, L.N.; SILVA, M.B.R.; FERNANDES, P.D.; CHAVES, L.H.G.; DANTAS NETO, J. \& GHEYI, H.R. Crescimento do pinhão-manso irrigado com águas salinas em ambiente protegido. R. Bras. Eng. Agric. Amb., 13:551-558, 2009.

NEVES, A.L.R.; LACERDA, C.F.; GUIMARÃES, F.V.A.; HERNANDEZ, F.F.F.; SILVA, F.B.; PRISCO, J.T. \& GHEYI, H.R. Acumulação de biomassa e extração de nutrientes por plantas de feijão-de-corda irrigadas com água salina em diferentes estádios de desenvolvimento. Ci. Rural, 39:758-765, 2009.
NOBRE, R.G.; GHEYI, H.R.; ANDRADE, L.O.; SOARES, F.A.L. \& NASCIMENTO, E.C.S. Crescimento do girassol irrigado com água residuária e adubação orgânica. R. DAE, 3:50-60, 2009.

NOVAIS, R.F.; NEVES, J.C.L. \& BARROS, N.F. Ensaio em ambiente controlado. In: OLIVEIRA, A.J. Métodos de pesquisa em fertilidade do solo. Brasília, Embrapa-SEA, 1991. p.189-253.

OLIVEIRA, A.M.; OLIVEIRA, A.M.P.; DIAS, N.S. \& MEDEIROS, J.F. Irrigação com água salina no crescimento inicial de três cultivares de algodão. Irriga, 13:467-475, 2008 .

POPOVA, O.V.; ISMAILOV, S.F.; POPOVA, T.N.; DIETZ, K.J. \& GOLLDACK, D. Salt-induced expression of NADPdependent isocitrate dehydrogenase and ferredoxin-dependent glutamate synthase in Mesembryanthemum crystallinum. Planta, 215:906-913, 2002.

PRADO, R.M. \& LEAL, R.M. Desordens nutricionais por deficiência em girassol var. Catissol-01. Pesq. Agropec. Trop., 36:187-193, 2006.

RHOADES, J.D.; KANDIAH, A.M. \& MARSHALI, A.M. Uso de águas salinas para produção agrícola. Campina Grande, Universidade Federal da Paraíba, 2000. 117p. (Estudos da FAO - Irrigação e Drenagem, 48)

RIBEIRO, M.C.C.; MARQUES, M.B. \& AMARRO FILHO, J. Efeito da salinidade na germinação de sementes de quatro cultivares de girassol (Helianthus annuus L.). R. Bras. Sem., 250:281-284, 2001.

RUBinigg M.; POSTHUMUS, F.; FERSCHKE, M.; ELZENGA, J.T.M. \& STULEN, I. Effects of $\mathrm{NaCl}$ salinity on N-nitrate fluxes and specific root length in the halophyte Plantago maritima L. Plant Soil, 250:201-213, 2003.

SILVA, M.L.O.E.; FARIAS, M.A.; MORAIS, A.R.; ANDRADE, G.P. \& LIMA, E.M.C. Crescimento e produtividade do girassol cultivado na entressafra com diferentes lâminas de água. R. Bras. Eng. Agric. Amb., 11:482-488, 2007.

TESTER, M. \& DAVENPORT, R. $\mathrm{Na}^{+}$tolerance and $\mathrm{Na}^{+}$ transport in higher plants. Ann. Bot., 91:503-527, 2003.

TRAVASSOS, K.D.; SOARES, F.A.L.; GHEYI, H.R.; SILVA, D.R.S.; NASCIMENTO, A.K.S. do; DIAS, N. da S. Produção de aquênio do girassol irrigado com água salobra. R. Bras Eng Agri e Ambiental, 15:371-376, 2011.

VIANA, A.P.; BRUCKNER, C.H.; MARTINEZ, H.E.P.; HUAMAN, C.A.M. \& MOSQUIM, P.R. Teores de Na, K, $\mathrm{Mg}$, e Ca em porta-enxertos de videira em solução salina. Sci. Agric., 58:187-191, 2001. 